\title{
Growth response of Pinus tabulaeformis to climate along an elevation gradient in the eastern Qinling Mountains, central China
}

\author{
Jiangfeng Shi ${ }^{1,2, *}$, Jinbao $\mathrm{Li}^{3}$, Edward R. Cook ${ }^{4}$, Xiaoye Zhang ${ }^{5}$, Huayu Lu ${ }^{1}$ \\ ${ }^{1}$ School of Geographic and Oceanographic Sciences, Institute for Climate and Global Change Research, Nanjing University, \\ Nanjing 210093, PR China \\ ${ }^{2}$ Nanjing Institute of Geography and Limnology, Chinese Academy of Sciences, Nanjing 210008, PR China \\ ${ }^{3}$ International Pacific Research Center, University of Hawaii at Manoa, Honolulu, Hawaii 96815, USA \\ ${ }^{4}$ Lamont-Doherty Earth Observatory, Columbia University, Palisades, New York 10964, USA \\ ${ }^{5}$ Chinese Academy of Meteorological Sciences, China Meteorological Administration, Beijing 100081, PR China
}

\begin{abstract}
Tree growth response to climate is not well understood in the eastern Qinling Mountains of central China, an East Asian monsoon dominated region. In this study, we developed 4 robust tree-ring width chronologies using Chinese pine Pinus tabulaeformis along an elevation gradient. The 4 chronologies were significantly correlated with each other. Through standard correlation function analysis, we found that each of the 4 chronologies correlated negatively with temperature, especially with maximum temperature in May and June, and positively with precipitation from prior December to current May. Principal component analysis and composite analysis of years when extremely narrow rings were common to all 4 chronologies confirmed this relationship. However, precipitation in the current September and October was positively correlated to tree growth at lower sites and negatively at higher ones, and temperature stress effects increased with elevation. The findings will help understand the growth response of this tree species to climate change in the southern part of its range, and provide critical information for future climate reconstructions using this tree species in humid or semi-humid regions.
\end{abstract}

KEY WORDS: Tree ring · Growth response • Pinus tabulaeformis • Qinling Mountains · Central China Resale or republication not permitted without written consent of the publisher

\section{INTRODUCTION}

The regional and seasonal expression of climate change determines the effects of greenhouse warming on ecosystems and society (Fischlin et al. 2007), and changes in precipitation and temperature play an important role in determining the effects of climate change on vegetation (Engler et al. 2011). However, the response of forests to climate change is complicated by differences in topography, elevation, and soil properties (Fritts 1976, Villalba et al. 1994, Ettl \& Peterson 1995, Buckley et al. 1997,
Liang et al. 2006, Fan et al. 2009). Recent studies have shown uphill shifts of species' distributions in response to historical warming (Theurillat \& Guisan 2001, Beniston 2003, Fagre et al. 2003, Dang et al. 2010a), which has led to widespread expectation of continued uphill shifts in response to future warming. Meanwhile, downhill shifts in plant species' optimum elevations have also been observed, which could be explained by species' niches tracking regional changes in climatic water balance rather than temperature (Crimmins et al. 2011). The present study addresses these issues by inves- 
tigating the growth response of Chinese pine Pinus tabulaeformis to climate factors along an elevation gradient in the southern part of its range in central China.

Chinese pine is widely distributed in China, ranging from $31^{\circ} \mathrm{N}$ to $44^{\circ} \mathrm{N}$ and from $101^{\circ} 30^{\prime} \mathrm{E}$ to $124^{\circ} 45^{\prime} \mathrm{E}$ (EBFC 2003). The responses of this tree species to climate have been well investigated in arid and semi-arid China, indicating that precipitation prior to and during the growing season is the primary factor limiting tree growth and that higher temperatures in the growing season enhance water stress through increasing evapotranspiration (Liu et al. 2004, 2005, 2009, Li et al. 2007, Shi et al. 2008, Liang et al. 2009). On the basis of these tree growth-climate relationships, many precipitation or soil moisture-related reconstructions have been conducted in arid and semi-arid China (Liu et al. 2004, 2005, Li et al. 2007). In the Qinling Mountains, several dendrochronological studies have been undertaken (Hughes et al. 1994, Shao \& Wu 1994, Garfin et al. 2005, Dang et al. 2007, 2009, 2010b). With respect to Chinese pine, one study found a significant positive correlation between ring width and mean temperature from prior September to current April on the southern slope, and a significant negative correlation between tree growth and mean May to July tempera-

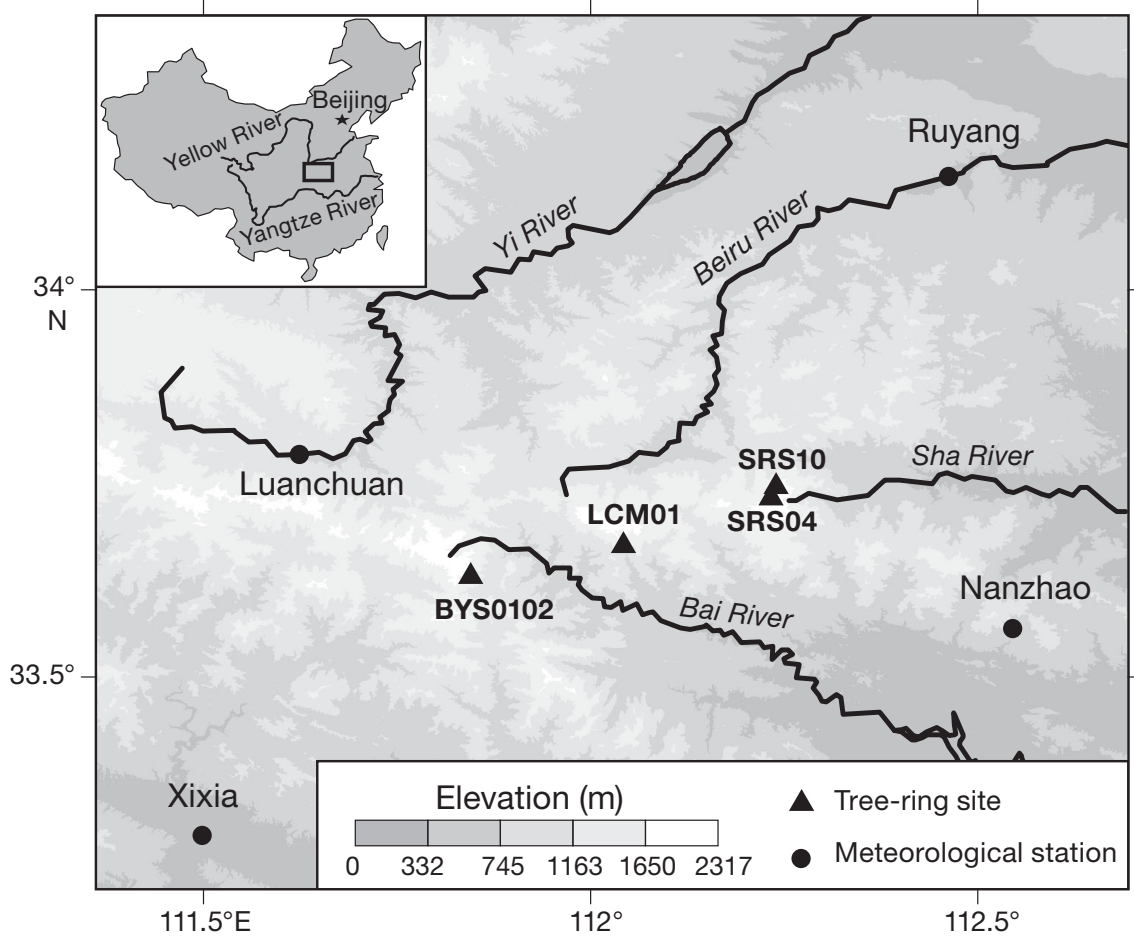

Fig. 1. The 4 tree-ring sampling sites and 4 meteorological stations in the eastern Qinling Mountains, central China ture on the northern slope (Liu et al. 2009); another study revealed a significant negative correlation between tree growth and mean May to July temperature (Tian et al. 2009). However, how this tree species responds to climate in humid and semihumid regions is still poorly understood, largely due to the very limited number of dendrochronological studies of this species in these regions. This situation has prevented large-scale climate reconstructions using Chinese pine. To address these challenges, we collected tree-ring samples of Chinese pine along an elevation gradient in the eastern Qinling Mountains, a semi-humid region controlled by the East Asian monsoon. We built 4 Chinese pine tree-ring width chronologies along the elevation gradient, and explored the relationships between tree growth and climate factors (precipitation and temperature) at different elevations.

\section{MATERIALS AND METHODS}

\subsection{Study area and climatic data}

The Qinling Mountains extend $1600 \mathrm{~km}$ from east to west, thereby forming an important watershed between China's 2 great rivers, the Yangtze River and the Yellow River (Fig. 1). The mountain range is situated in the transitional zone between subtropical and warm-temperate zones, making it a biologically rich area and one that is sensitive to climatic change. Our study area is a branch of the eastern Qinling Mountains, also called Mount Funiu. Elevation of the highest peak is $2192 \mathrm{~m}$ above sea level ( $\mathrm{m}$ asl).

Climate data used in this study include regional monthly maximum, mean and minimum temperature and monthly total precipitation. The instrumental data were obtained from 4 meteorological stations (Luanchuan, $33^{\circ} 47^{\prime} \mathrm{N}, 111^{\circ} 38^{\prime} \mathrm{E}$; Xixia, $33^{\circ} 18^{\prime} \mathrm{N}$, $111^{\circ} 30^{\prime} \mathrm{E}_{;}$Ruyang, $34^{\circ} 09^{\prime} \mathrm{N}, 112^{\circ}$ $28^{\prime} \mathrm{E}$; Nanzhao, $33^{\circ} 34^{\prime} \mathrm{N}, 112^{\circ} 33^{\prime} \mathrm{E}$ ) around the sampling sites (Fig. 1), all of which cover the period from 1958 to 2005. As shown in Fig. 2, annual precipitation decreases from southeast to northwest and increases with elevation. Annual mean temperature in Luanchuan is about 2 to $3^{\circ} \mathrm{C}$ lower 

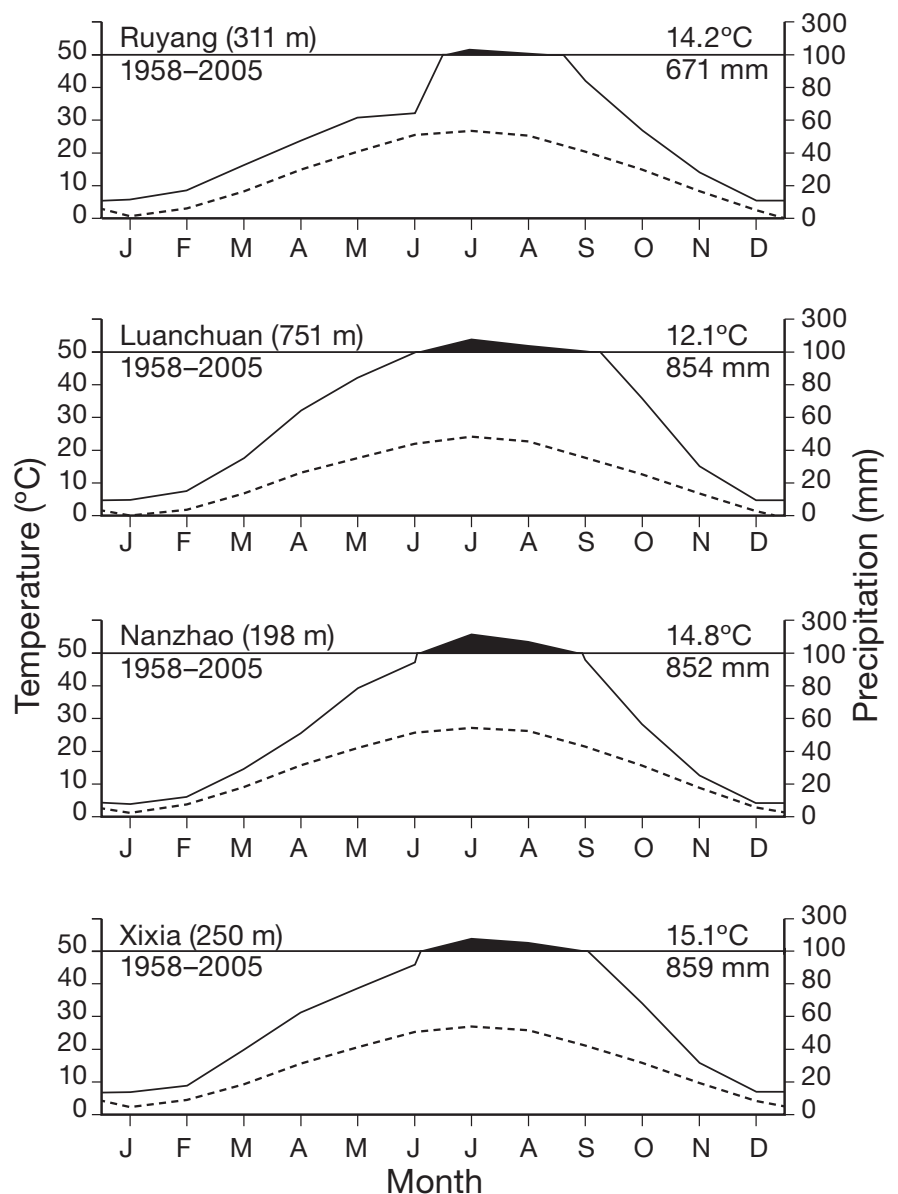

Fig. 2. Monthly mean air temperature (lower line) and total precipitation (upper line) at 4 meteorological stations in the eastern Qinling Mountains, central China. Black shading indicates a shift in scale, as indicated for precipitation on the right-hand $y$-axis

than that at the other 3 sites. Most of the annual precipitation falls in the summer half-year, and is brought by the East Asian Summer Monsoon that moves from southeast to northwest. Considering that the sampling sites are located in an area bounded by the 4 stations, we averaged the monthly temperature and monthly precipitation data from the 4 meteorological stations to represent regional climate. These averaged climate data are used for correlation analysis of the 4 chronologies at different elevations, and might be somewhat different from actual climate data at each elevation. However, as there are no climate observations or available precipitation and temperature transfer functions for each elevation, we consider the current climate data can help broadly assess the climate-tree growth relationships in this region. Therefore, the following analysis is based on the spatially averaged climate data.

\subsection{Tree-ring data}

We collected increment cores of Chinese pine from 4 sites at different elevations (Fig. 1). The sampling sites, located in Baiyunshan (BYS), Longchiman (LCM), and Shirenshan (SRS) National Reserves, were: BYS0102 $\left(33^{\circ} 38^{\prime} \mathrm{N}, 111^{\circ} 51^{\prime} \mathrm{E}\right), \mathrm{LCM}^{\prime} 1\left(33^{\circ} 41^{\prime} \mathrm{N}, 112^{\circ} 3^{\prime} \mathrm{E}\right)$, SRS04 $\left(33^{\circ} 44^{\prime} \mathrm{N}, 112^{\circ} 14^{\prime} \mathrm{E}\right)$ and SRS10 $\left(33^{\circ} 44^{\prime} \mathrm{N}\right.$, $\left.112^{\circ} 15^{\prime} \mathrm{E}\right)$. A few samples of BYS0102 and all samples of SRS10 were collected in early June of 2006. Other samples of BYS0102 and all samples of LCM01 and SRS04 were collected in early June of 2008. All trees at these sites grow on thin soils on the peaks of mountains that are difficult to access, and they are sparsely distributed. Thus, the effects of slopes, orientations, and inter-tree competition are minimized. The longest distance among the sampling sites is only $45 \mathrm{~km}$ (from BYS0102 to SRS10). As a result, climate variation due to differences in elevation is the dominant factor affecting tree growth at each site.

Following the standard dendrochronological techniques (Cook \& Kairiukstis 1990), 2 cores per tree were extracted using increment borers, and at least 20 trees were cored at each site (Table 1). Samples were processed using standard procedures (Stokes \& Smiley 1996), and then were visually cross-dated under a microscope. Each tree-ring width was measured to $0.001 \mathrm{~mm}$ precision using the LINTAB 5.0 system. Dating and measurement errors were further checked with the COFECHA computer program (Holmes 1983). Subsequently, each ring-width chronology was developed using the ARSTAN program (Cook 1985) by removing biological growth trends while preserving variations that were likely related to climate. All the measurement series were detrended using fitted negative exponential curves or linear regression curves. A cubic spline with a 50\% frequency-response cutoff equal to $67 \%$ of the series length was also used in a few cases (0 of 27 cores from BYS0102, 2 of 43 cores from LCM01, 2 of 57 cores from SRS04, and 2 of 33 cores from SRS10) when anomalous growth trends occurred. The ratios between original ring widths and the fitted curves are calculated as the detrended series. Autoregressive modeling was used to remove much of the autoregressive properties in the detrended series. The resulting series were biweight-averaged to produce a residual chronology (the RES chronology generated by ARSTAN) for each site (Fig. 3). As the sample size generally declines in the early portion of a treering chronology, we used the subsample signal strength (Wigley et al. 1984) with a threshold of 0.85 to identify the most reliable time span of each 
Table 1. Residual tree-ring width chronologies from 4 sampling sites in the eastern Qinling Mountains, central China (see Section 2.2. for explanation of site codes). T/C: numbers of trees/cores sampled; TRW: tree-ring width (mean \pm SD); $\hat{c}$ : estimated constant basal area increment for each ring width series (mean and range); SD: standard deviation; MS: mean sensitivity; AC1: first-order autocorrelation; $\mathrm{R}_{\mathrm{bt}}$ : mean inter-series correlation; EPS: expressed population signal; PC1: percent variance explained by the first principal component; SNR: signal-to-noise ratio

\begin{tabular}{|c|c|c|c|c|c|c|c|}
\hline Site & $\begin{array}{l}\text { Altitude } \\
(\mathrm{m})\end{array}$ & $\mathrm{T} / \mathrm{C}$ & $\begin{array}{l}\text { TRW } \\
(\mathrm{mm})\end{array}$ & $\begin{array}{c}\hat{C} \\
\left(\mathrm{~mm}^{2} \mathrm{yr}^{-1}\right)\end{array}$ & & age & Time span \\
\hline BYS0102 & $1200-1300$ & $14 / 27$ & $1.46 \pm 0.63$ & $387.5(138.9-871.7)$ & & & $1841-2007$ \\
\hline LCM01 & $1340-1400$ & $22 / 43$ & $1.28 \pm 0.64$ & $311.3(76.0-764.7)$ & & & $1843-2007$ \\
\hline SRS04 & 1630-1720 & $29 / 57$ & $1.31 \pm 0.64$ & $369.5(70.3-1291.2)$ & & & $1774-2007$ \\
\hline SRS10 & 1850-1950 & $20 / 33$ & $1.04 \pm 0.54$ & $242.1(23.0-1275.4)$ & & & 1799-2005 \\
\hline Site & $\mathrm{SD}^{\mathrm{a}}$ & $\mathrm{MS}^{\mathrm{a}}$ & $\mathrm{AC} 1^{\mathrm{a}}$ & $\mathrm{R}_{\mathrm{bt}}^{\mathrm{b}}$ & $\mathrm{EPS}^{\mathrm{b}}$ & $\mathrm{PC} 1^{\mathrm{b}}(\%)$ & $\mathrm{SNR}^{\mathrm{b}}$ \\
\hline BYS0102 & 0.35 & 0.26 & 0.53 & 0.43 & 0.93 & 47 & 12.6 \\
\hline LCM01 & 0.38 & 0.29 & 0.53 & 0.47 & 0.96 & 49 & 25.5 \\
\hline SRS04 & 0.33 & 0.25 & 0.52 & 0.40 & 0.97 & 42 & 29.9 \\
\hline SRS10 & 0.39 & 0.27 & 0.60 & 0.35 & 0.92 & 40 & 11.5 \\
\hline
\end{tabular}

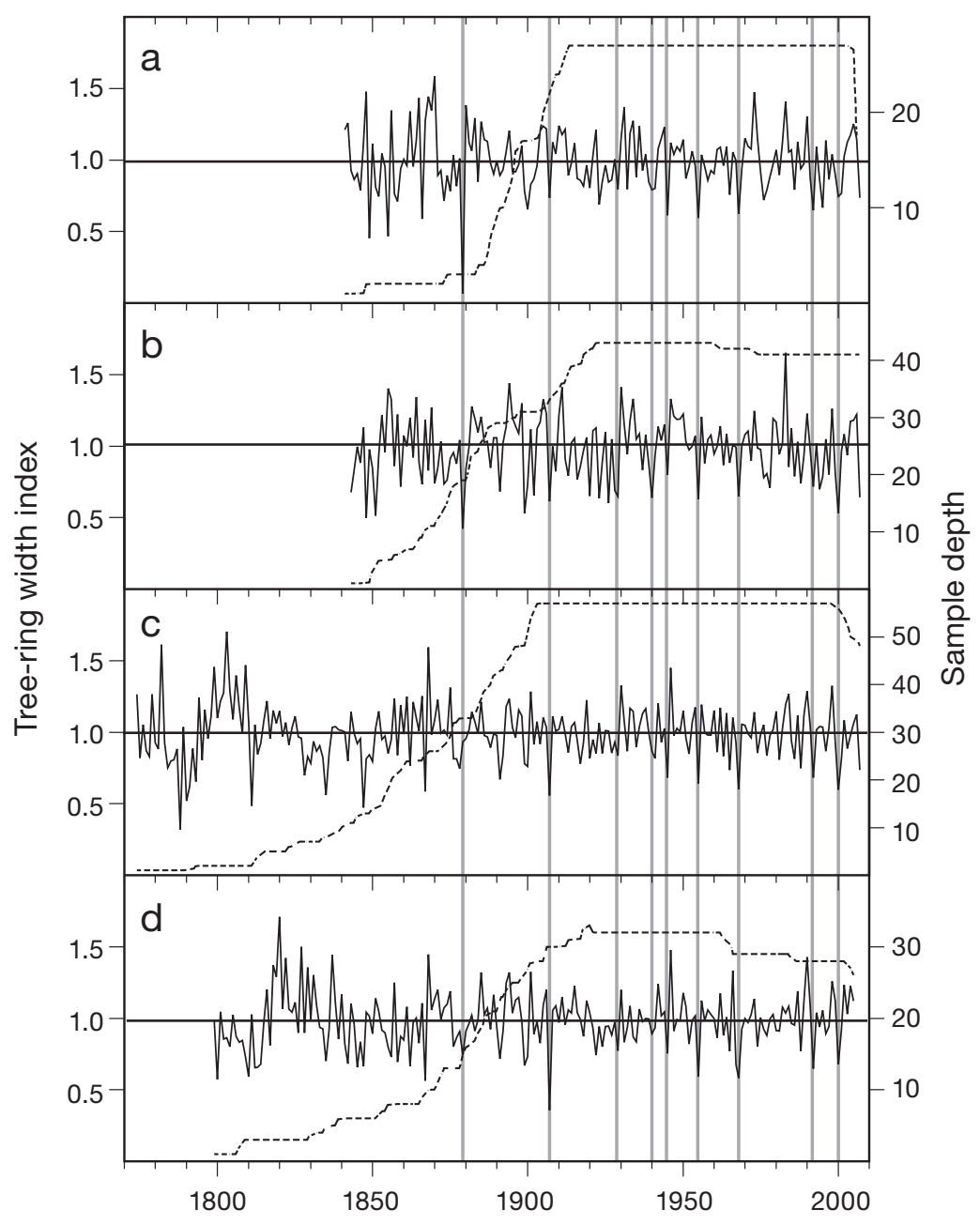

chronology. The BYS0102, LCM01, SRS04 and SRS10 residual chronologies spanned the periods 1841-2007, 1843-2007, 1774-2007, and 17992005, respectively, and the most reliable time spans were from 1887-2007, 1857-2007, 1826-2007, and 18522005, respectively.

\subsection{Statistical analysis}

Several descriptive statistics were used to evaluate the quality of the chronologies: mean sensitivity and standard deviation, mean correlation among all series of each site, signal/ noise ratio, expressed population signal (EPS), and the variance explained by the first principal component (PC1)

Fig. 3. Residual tree-ring width chronologies (solid line) and their sample depth (dashed line) from 4 sampling sites in the eastern Qinling Mountains, central China: (a) BYS0102, (b) LCM01, (c) SRS04, and (d) SRS10 (see Section 2.2 for explanation of site abbreviations). The vertical straight lines indicate common narrow rings among the 4 chronologies 
(Fritts 1976). Principal component analysis was used to classify the chronologies, and the resulting components were used to explore how climate caused their structural similarities and/or differences that might be related to site elevations. The robust principal components were calculated from the correlation matrix of the 4 chronologies. This transformation is defined in a way that PC1 has as high a variance as possible, and each succeeding component has the highest variance possible under the constraint that it be orthogonal to the preceding components. Correlation and principal component analyses were done using the software Statistica 6.0 (StatSoft). In order to assess the relations between ring-width chronologies and climate, Pearson's correlations were computed between tree-ring chronologies, the first 2 principal components of the 4 chronologies and temperature and precipitation over a 16 mo window from July of the year before tree growth until October of the current year. The significance level was 0.05 .

\section{RESULTS AND DISCUSSION}

\subsection{Characteristics of tree-ring chronologies}

The highest site, SRS10, has an average ring width of $1.04 \mathrm{~mm}$, while the lowest site, BYS0102, has an average width of $1.46 \mathrm{~mm},>41 \%$ wider (Table 1). The mid-elevation sites LCM01 and SRS04 have average ring widths of 1.28 and $1.31 \mathrm{~mm}$, respectively. Basal area increment $\hat{c}$ represents overall tree growth better than a linear measurement (Valentine 1985, LeBlanc 1990, Bigler \& Bugmann 2003, Biondi \& Qeadan 2008), and was also calculated (see Eq. 12 in Biondi \& Qeadan 2008). It decreased with increasing elevation (Table 2). In order to evaluate the influence of tree age on ring width and the estimated basal area increment, the samples from the 4 sites were pooled, and the correlation coefficients between tree age and ring width and between tree age and the estimated basal area increment were calculated, and found to be -0.52 and -0.30 , respectively

Table 2. Correlation matrix of 4 tree-ring width chronologies over their common period 1887-2005

\begin{tabular}{|lccc|}
\hline & BYS0102 & LCM01 & SRS04 \\
\hline LCM01 & 0.75 & & \\
SRS04 & 0.57 & 0.66 & \\
SRS10 & 0.48 & 0.56 & 0.80 \\
\hline
\end{tabular}

( $N=160$ ), both significant at 0.01 level. Therefore, the general decreases of ring width and basal area increment with elevation cannot be attributed to elevation effects here. Standard deviations and mean sensitivities vary from 0.33 to 0.39 and 0.25 to 0.29 , respectively. The highest site has the largest value of the first-order autocorrelation, but the smallest value of inter-series correlation. The EPS value increases with tree/core numbers by definition (Wigley et al. 1984). The variances explained by the first principal components for the lower sites (i.e. BYS0102 and LCM01) are larger than those of the higher sites (i.e. SRS04 and SRS10). However, the signal-to-noise ratios are higher for middle elevation sites, which may be due to the larger number of cores.

\subsection{Correlations between the chronologies}

The correlations of each pair of the 4 chronologies are significant at the 0.01 level (Table 2), indicating that there are common climatic factors influencing tree growth at each elevation. The smaller the difference in elevation between 2 sites, the more significant is their correlation. The closest 2 pairs of chronologies, BYS0102-LCM01 and SRS04-SRS10, have the highest correlations of 0.75 and 0.80 , respectively. Therefore, site elevation is a very important factor in determining the similarity of site chronologies.

\subsection{Tree growth and climate}

We calculated the correlations of the 4 residual chronologies with monthly maximum, mean, minimum temperatures and monthly total precipitation. As shown in Fig. 4, a general feature is that tree growth responds positively to precipitation from prior December to current May at all 4 sites, indicating that there is water stress prior to and at the beginning of the growing season. In northern China, dendrochronological studies of Chinese pine indicate that the limiting effect of precipitation extends to July (Liu et al. 2005, 2007, 2010, 2011, Li et al. 2007). A process-based modeling analysis also showed that precipitation prior to and during the growing season has significant effects on Chinese pine growth in semi-arid areas of north central China (Shi et al. 2008). However, water stress only extends to May in this study, reflecting the early arrival of the East Asian Monsoon in the region, which explains why tree growth shows no relation with July and August precipitation. Tree growth is correlated positively 


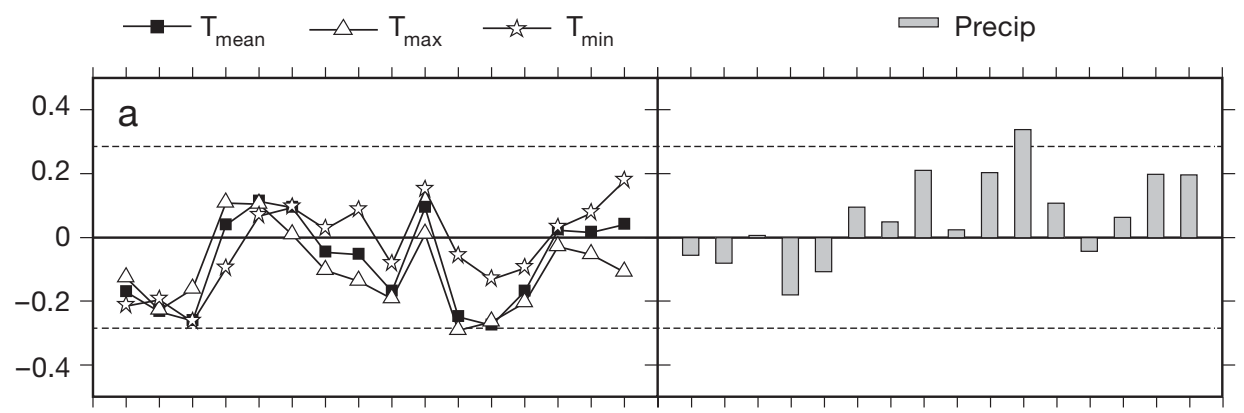

JASONDJFMAM J JASO JASOND JFMAM J JASO

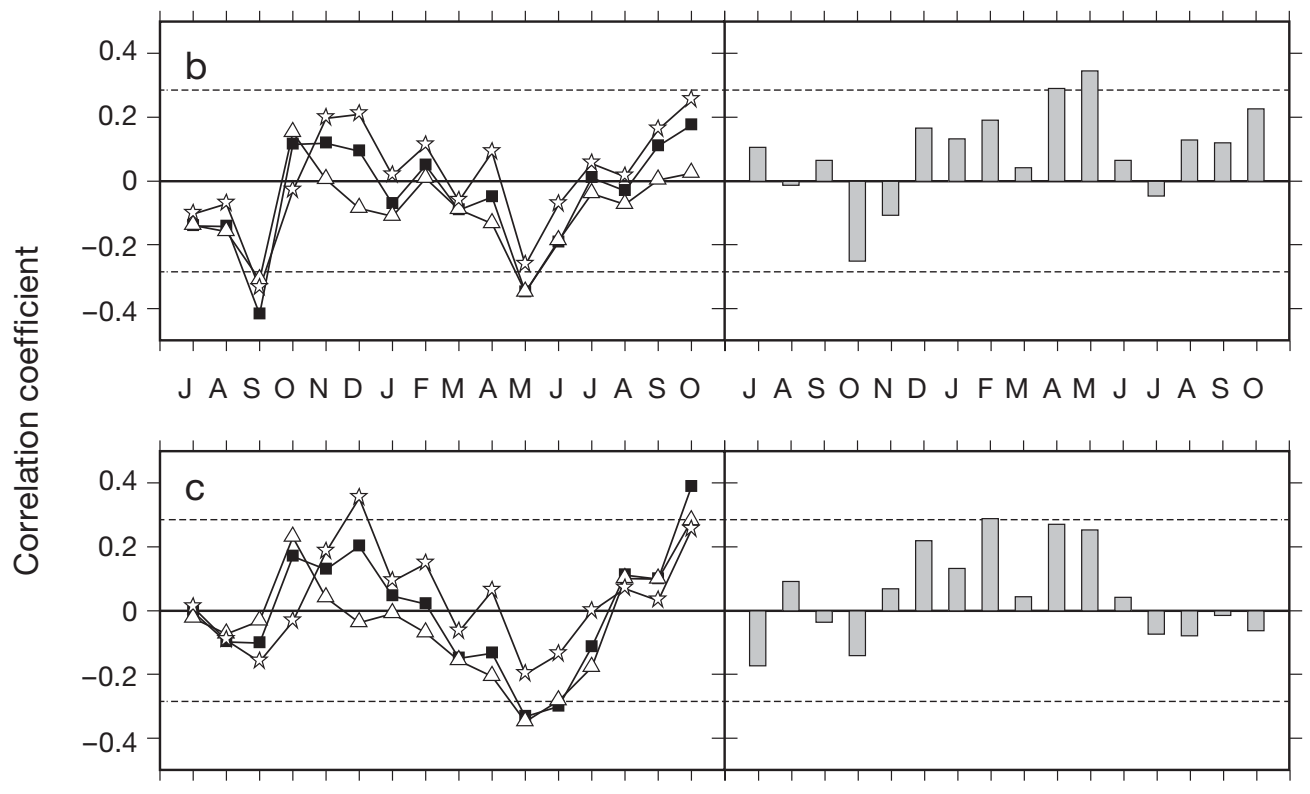

JASOND JFMAM J JASO JASOND JFMAM J JASO

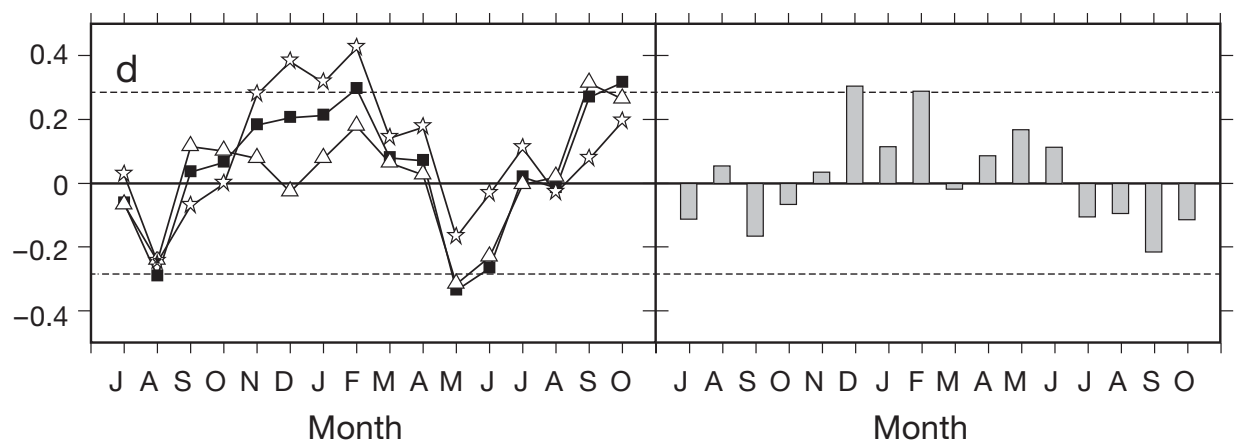

Fig. 4. Correlations of monthly mean ( $\left.\mathrm{T}_{\text {mean }}\right)$, maximum $\left(\mathrm{T}_{\max }\right)$, and minimum temperature $\left(\mathrm{T}_{\min }\right)$ and monthly total precipitation for 1958-2005 with residual tree-ring width chronologies: (a) BYS0102, (b) LCM01, (c) SRS04, and (d) SRS10. The dashed lines indicate the 0.05 significance levels

with precipitation in September and October at the 2 lower sites (BYS0102 and LCM01), but negatively at the 2 higher sites (SRS04 and SRS10). It was positively correlated with temperature in September and October, mainly at the 2 higher sites. July is the hottest month of a year. From then on, temperature decreases and its limiting effect strengthens, especially at higher sites. There are statistically significant negative inter-correlations between maximum temperatures and precipitation in September and October (Table 3). When temperature decreases below a certain point, it begins to limit tree growth 
Table 3. Correlations between maximum temperature and precipitation for the period 1958-2005 in data from 4 meteorological stations in the eastern Qinling Mountains, central China. *Values significant at the 0.05 level

\begin{tabular}{|c|c|c|c|c|c|c|c|c|c|c|c|c|}
\hline Month & 1 & 2 & 3 & 4 & 5 & 6 & 7 & 8 & 9 & 10 & 11 & 12 \\
\hline Correlation coefficient & $-0.53^{*}$ & -0.26 & $0.39^{*}$ & $0.51^{*}$ & $-0.55^{*}$ & $-0.42^{*}$ & $-0.34^{*}$ & $-0.50^{*}$ & $-0.65^{*}$ & $-0.59^{*}$ & $-0.57^{*}$ & $-0.56^{*}$ \\
\hline
\end{tabular}

directly; at the same time the negative relationships between maximum temperature and precipitation leads to negative effects of precipitation on tree growth in September and October. This mainly affects higher sites, such as SRS10, where precipitation is higher and temperatures are lower, compared to other sites. This relationship was also found in the Helan Mountains of north central China, where a process-based model study showed that the percentage of days with growth limitation was related to temperature increases, while that related to soil moisture decreases in the late growing season (Shi et al. 2008). Further investigation of the inversion of the relation of tree growth and precipitation in September and October is required.

Tree growth is positively influenced by winter temperature prior to the growing season, in October to December at BYS0102 and LCM01, October to February at SRS04, and October to March at SRS10 (Fig. 4). The number of limiting months increases with elevation. Moreover, the higher the sampling site, the stronger are the effects of prior winter temperature on tree growth. When prior winter temperature limits tree growth, it is the minimum temperature that plays the critical role. There are no significant correlations between tree growth and monthly minimum temperature during the period of prior winter at BYS0102 and LCM01, but 1 significant correlation was recorded at SRS04 $(r=0.35$ in prior December) and 3 significant correlations at SRS10 $(\mathrm{r}=0.38,0.32$, and 0.42 in prior December, January and February, respectively). The influence of winter temperature on tree growth was also found for Pinus taiwanensis Hayata in the lower reaches of the Yangtze river in southeast China (Shi et al. 2010), Pinus armandii Franch in the eastern Qinling Mountains (Shi et al. 2009), Pinus tabulaeformis in the southern Qinling Mountains (Liu et al. 2009), Juniperus przewalskii in the Xiqing Mountains of the northeastern Tibetan Plateau (Gou et al. 2007), Abies chensiensis in the Jiuzhaigou region of southwest China (Song et al. 2007), Sabina przewalskii and Picea crassifolia on the northeast Tibetan Plateau (Liang et al. 2006), and Picea balfouriana in western Sichuan Province of China (Shao \& Fan, 1999). Increased winter temperature in areas of inconsistent snow pack may reduce winter damage to roots, resulting in less growth limitation (Pederson et al. 2004). Therefore, winter temperatures have a strong influence on tree growth for many species from humid to semi-humid regions and in high mountains.

May to June temperatures were negatively correlated with tree growth, and it was maximum temperature, not minimum temperature (nighttime temperature), that played the limiting role (Fig. 4). Significant correlations between tree growth and maximum temperatures occurred in May $(\mathrm{r}=-0.29$, $-0.35,-0.35$ and -0.32 at BYS0102, LCM01, SRS04 and SRS10, respectively). Plant stomata open in the daytime when there is a large amount of sunshine, which increases water evaporation and exaggerates water stress in the early growing season when there is less monsoon-related precipitation in the study area. These negative correlations were consistent with an expected drought response of trees to increasing evapotranspiration when temperature increased to the level of sustaining tree growth but precipitation did not catch up. With further increase of precipitation in July and August, water stress was largely alleviated, and tree growth was no longer influenced by temperature.

\subsection{Principal components of the chronologies and climate}

We extracted the first 2 principal components (PC1 and PC2) of the 4 residual chronologies, which explained $89.26 \%$ of the total variance (Fig. 5). The PC1 loadings are $-0.82,-0.87,-0.89$ and -0.83 , and the PC2 loadings are $-0.49,-0.32,0.31$ and 0.47 , for BYS0102, LCM01, SRS04 and SRS10 chronologies, respectively. As shown in Fig. 5, the 4 chronologies have similar PC1 loadings, indicating that the PC1 represents their common signals. However, PC2 loadings highlight the differences between the lower and the higher sites: lower sites BYS0102 and LCM01 show negative loadings while higher sites SRS04 and SRS10 show positive loadings.

Correlations were calculated between climate factors (monthly maximum, mean, and minimum temperature, monthly precipitation) and PC1 and PC2, 


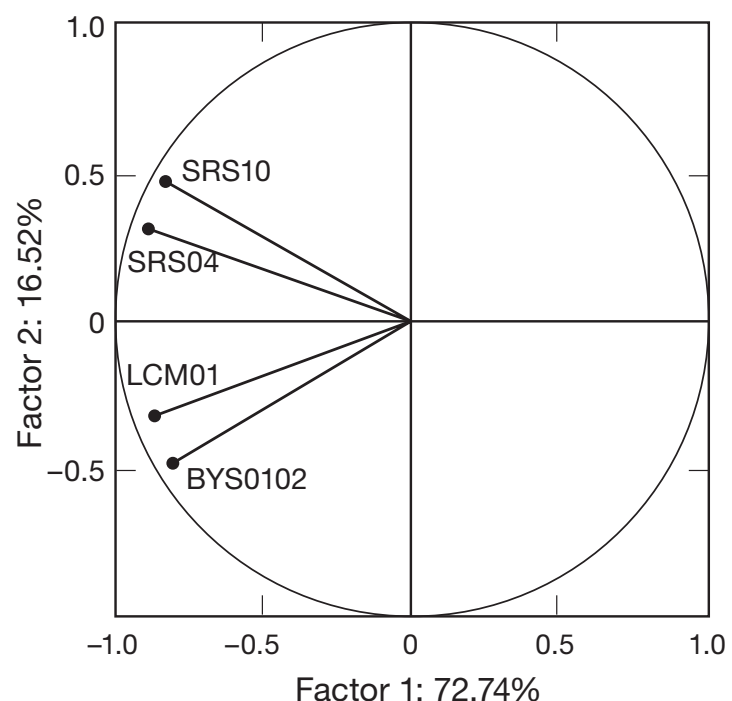

Fig. 5. Factor loadings of the 4 tree-ring residual chronologies and the variances explained by the first and the second principal components (PC1 and PC2)

respectively (Fig. 6). PC1 is correlated negatively with prior December minimum temperature $(\mathrm{r}=$ -0.30), and positively with maximum and mean temperatures in May ( $\mathrm{r}=0.38$ and 0.37 , respectively) and in June ( $r=0.29$ and 0.31 , respectively). Strong correlations were found with precipitation from prior December to current May, with significant correlations in February $(r=-0.29)$ and May $(r=-0.32)$. PC2 is correlated positively with maximum and mean temperature of prior September $(r=0.33$ and 0.37 , respectively), maximum temperature in September ( $\mathrm{r}=0.31)$, and maximum and mean temperature in October ( $r=0.40$ and 0.30 , respectively). Strong negative correlations were found with precipitation from August to October, with significant correlations in September $(r=-0.37)$ and October $(r=-0.37)$.

In general, common signals of the 4 chronologies were dominated by maximum and mean temperatures in May and June, and precipitation from prior December to current May. Tree growth at all 4 sites benefits from the lower maximum and mean temperatures in May and June and from more precipitation from prior December to current May. Tree growth at higher sites benefits from higher maximum temperature in September, higher maximum and mean temperatures in October, and less precipitation in September and October. With the decrease of site elevation, the relationship with precipitation becomes less strong and is then reversed.

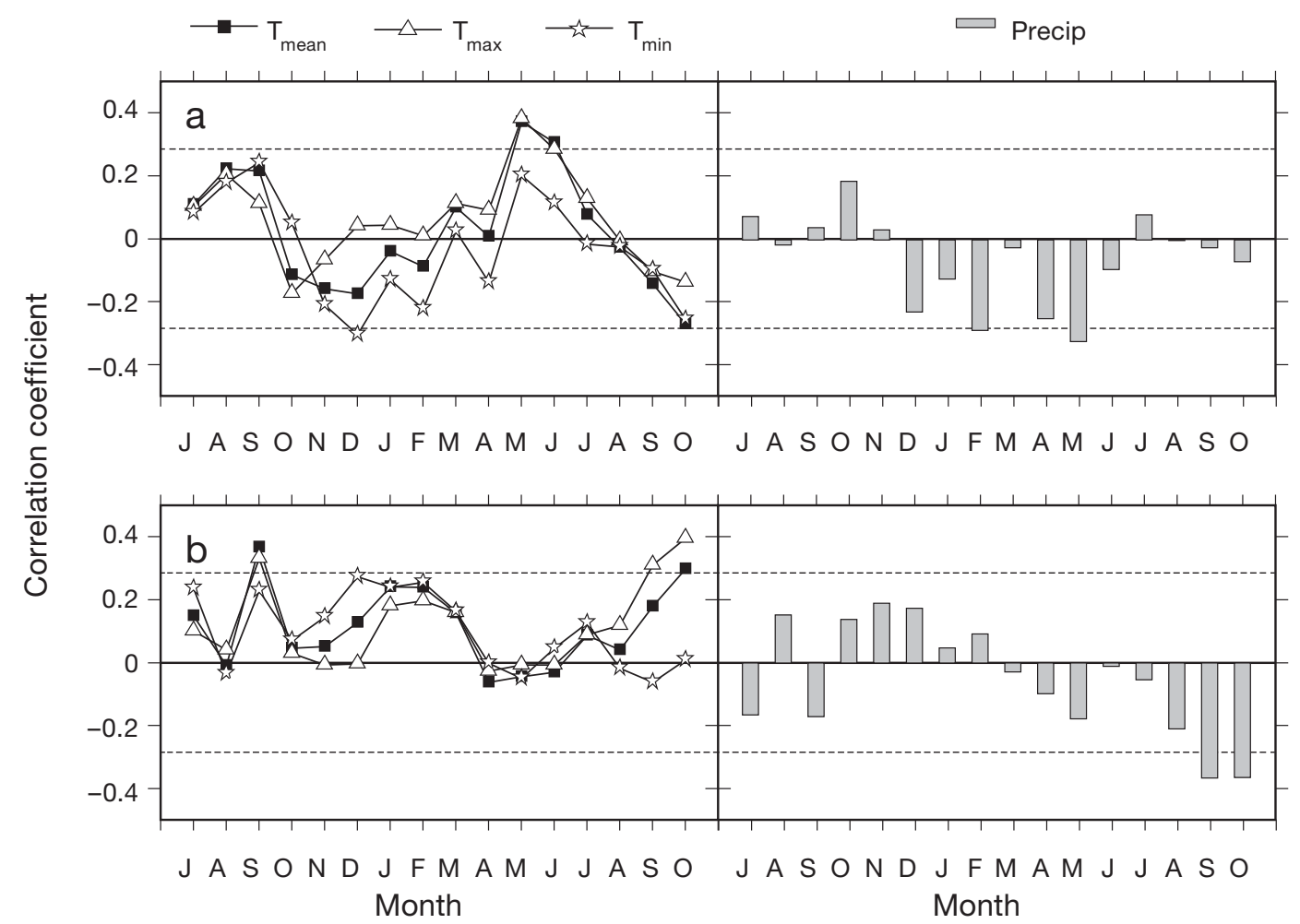

Fig. 6. Correlations of monthly mean $\left(\mathrm{T}_{\text {mean }}\right)$, maximum $\left(\mathrm{T}_{\max }\right)$, and minimum temperature $\left(\mathrm{T}_{\min }\right)$ and monthly total precipitation for 1958-2005 with principal components of the 4 tree-ring width chronologies: (a) PC1, and (b) PC2. The dashed lines indicate the 0.05 significance levels 


\subsection{Formation of extremely narrow rings}

During the process of crossdating, we found extremely narrow rings that served as marker rings at all 4 sites (Fig. 3). Considering only the period 1958 to 2005, we compared tree-ring width with meteorological data to identify the climate factors that controlled the formation of extremely narrow rings. As shown in Fig. 3, these rings were formed in 1968, 1992 and 2000 in all 4 chronologies. When the 4 chronologies were averaged over their common reliable period from 1887 to 2005, the widths of these 3 narrow rings were outside of the range of 1 standard deviation, the probability of which was $<5 \%$.

We calculated the average values of monthly maximum, mean, and minimum temperatures and precipitation for the 3 years, and then subtracted their respective long-term mean values (Fig. 7). As shown above, common tree-ring patterns were mainly determined by temperature in May and June, and precipitation from prior December to current May. It was found that average monthly precipitation over the 3 years 1968, 1992 and 2000 was below its long-term mean from prior December to current May, especially in April and May, when precipitation was 53.3 and $30.2 \%$ below average. Temperature deviations
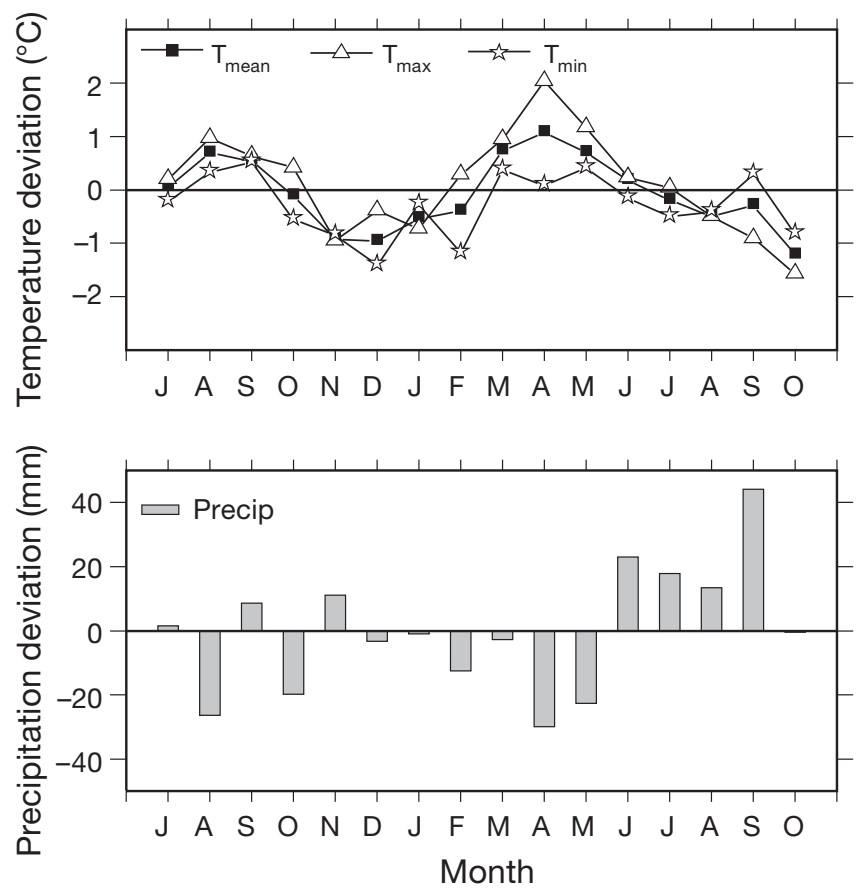

Fig. 7. Deviations of average monthly mean $\left(\mathrm{T}_{\text {mean }}\right)$, maximum $\left(\mathrm{T}_{\mathrm{max}}\right)$, and minimum temperature $\left(\mathrm{T}_{\min }\right)$ and monthly total precipitation for the years 1968, 1992 and 2000, when extremely narrow tree-rings were formed, from their long-term mean values for the period 1958-2005 were positive from March to May $(0.94,2.23$ and $1.17^{\circ} \mathrm{C}$, in March, April and May maximum temperatures, respectively). Therefore, we conclude that low precipitation before and in the early growing season (prior December to current May) and high temperatures in spring (March to May) together caused the formation of extremely narrow rings.

\section{CONCLUSIONS}

Chinese pine is distributed in a large region in China, from $31^{\circ} \mathrm{N}$ to $44^{\circ} \mathrm{N}$ and $101^{\circ} 30^{\prime} \mathrm{E}$ to $124^{\circ} 45^{\prime} \mathrm{E}$. Although the response of this tree species to climate has been widely investigated in the northern part of its range, where the climate is arid or semi-arid, little work has been done on the southern part of the range where the climate is humid or semi-humid. In this study, we developed 4 tree-ring width chronologies along an elevation gradient, and analyzed their response to climate using nearby meteorological records. We found that the similarities and differences among the 4 tree-ring width chronologies of Chinese pine are attributed to climatic factors. Their common ring-width patterns were determined by temperature in May and June and precipitation from prior December to current May. However, temperatures and precipitation in current September and October had a broadly opposite influence at the lower and the higher sites. This study provides critical information for climate reconstruction using Chinese pine in the southern part of its range, and further emphasizes the importance of winter temperature, especially at high sites in this region, on carbon cycles in the context of global warming. To the north of the study region, precipitation prior to and at the beginning of the growing season could be reconstructed using Chinese pine, but to the south, winter temperature is more likely to be reconstructed using this species. There is an ongoing warming and drying trend for all seasons in central and north China (Wang \& Zhou 2005, Zhai et al. 2005, Ma \& Fu 2006), which has been projected to continue for the next few decades (Tao et al. 2003). Under this type of climate change, Chinese pine is expected to reduce its capacity to sequester carbon, with the exception of the southern part of its range, where tree growth could benefit from the increase of winter and autumn temperatures, in particular at high elevation sites.

Acknowledgements. The authors thank J. Jiao, G. Wei, X. Deng, J. Shi, C. Yang, and Y. Shi for their help in the field and laboratory. We also thank 3 anonymous reviewers for 
their helpful comments. This research was jointly funded by the National Basic Research Program of China (973 Program) (No. 2010CB950104), NSFC Project (Nos. 40601106 and 40811120030), and the Priority Academic Program Development of Jiangsu Higher Education Institutions.

\section{LITERATURE CITED}

Beniston M (2003) Climatic change in mountain regions: a review of possible impacts. Clim Change 59:5-31

Bigler C, Bugmann H (2003) Growth-dependent tree mortality models based on tree rings. Can J For Res 33:210-221

Biondi F, Qeadan F (2008) A theory-driven approach to treering standardization: defining the biological trend from expected basal area increment. Tree-Ring Res 64:81-96

Buckley BM, Cook ER, Peterson MJ, Barbetti M (1997) A changing temperature response with elevation for Lagarostrobos franklinii in Tasmania, Australia. Clim Change 36:477-498

Cook ER (1985) A time series analysis approach to treering standardization. $\mathrm{PhD}$ thesis, University of Arizona, Tucson, AZ

Cook ER, Kairiukstis L (1990) Methods of dendrochronology: applications in the environmental sciences. Springer, New York, NY

> Crimmins SM, Dobrowski SZ, Greenberg JA, Abatzoglou JT, Mynsberge AR (2011) Changes in climatic water balance drive downhill shifts in plant species' optimum elevations. Science 331:324-327

Dang HS, Jiang MX, Zhang QF, Zhang YJ (2007) Growth responses of subalpine fir (Abies fargesii) to climate variability in the Qinling Mountain, China. For Ecol Manag 240:143-150

Dang HS, Jiang MX, Zhang YJ, Dang GD, Zhang QF (2009) Dendroecological study of a subalpine fir (Abies fargesii) forest in the Qinling Mountains, China. Plant Ecol 201: $67-75$

Dang HS, Zhang YJ, Jiang MX, Zhang QF (2010a) Growth performance and range shift of the subalpine fir (Abies fargesii) in the Qinling Mountains, China. Int J Sust Dev World 17:162-171

Dang HS, Zhang YJ, Zhang KR, Jiang MX, Zhang QF (2010b) Age structure and regeneration of subalpine fir (Abies fargesii) forests across an altitudinal range in the Qinling Mountains, China. For Ecol Manag 259:547-554

EBFC (Editorial Board of Forest in China) (2003) Forest in China, Vol 2. China Forestry Publishing House, Beijing (in Chinese)

Engler R, Randin CF, Thuiller W, Dullinger S and others (2011) 21st century climate change threatens mountain flora unequally across Europe. Glob Change Biol 17: 2330-2341

Ettl GJ, Peterson DL (1995) Growth response of subalpine fir (Abies lasiocarpa) to climate in the Olympic Mountains, Washington, USA. Glob Change Biol 1:213-230

Fagre DB, Peterson DL, Hessl AE (2003) Taking the pulse of mountains: ecosystem responses to climatic variability. Clim Change 59:263-282

Fan ZX, Brauning A, Cao KF, Zhu SD (2009) Growth-climate responses of high-elevation conifers in the central Hengduan Mountains, southwestern China. For Ecol Manag 258:306-313

Fischlin A, Midgley G, Price J, Leemans R and others (2007) Climate change 2007: impacts, adaptation and vulnerabil- ity. Contribution of Working Group II to the Fourth Assessment Report of the Intergovernmental Panel on Climate Change. Cambridge University Press, Cambridge

Fritts HC (1976) Tree rings and climate. Academic Press, London

Garfin G, Hughes M, Yu L, Burns J, Touchan R, Leavitt S, Zhisheng A (2005) Exploratory temperature and precipitation reconstructions from the Qinling Mountains, north-central China. Tree-Ring Res 61:59-72

Gou XH, Chen FH, Jacoby G, Cook E, Yang MX, Peng HF, Zhang Y (2007) Rapid tree growth with respect to the last 400 years in response to climate warming, northeastern Tibetan Plateau. Int J Climatol 27:1497-1503

Holmes RL (1983) Computer-assisted quality control in treering dating and measurement. Tree-Ring Bull 43:69-78

Hughes MK, Wu XD, Shao XM, Garfin GM (1994) A preliminary reconstruction of rainfall in north-central China since AD 1600 from tree-ring density and width. Quat Res 42:88-99

> LeBlanc DC (1990) Relationships between breast-height and whole-stem growth indices for red spruce on Whiteface Mountain, New York. Can J For Res 20:1399-1407

> Li JB, Chen F, Cook ER, Gou XH, Zhang YX (2007) Drought reconstruction for north central China from tree rings: the value of the Palmer Drought Severity Index. Int J Climatol 27:903-909

Liang EY, Shao XM, Eckstein D, Huang L, Liu XH (2006) Topography- and species-dependent growth responses of Sabina przewalskii and Picea crassifolia to climate on the northeast Tibetan Plateau. For Ecol Manag 236: $68-277$

Liang EY, Eckstein D, Shao XM (2009) Seasonal cambial activity of relict Chinese Pine at the northern limit of its natural distribution in North China - exploratory results. IAWA J 30:371-378

Liu Y, Shi JF, Shishov V, Vaganov E and others (2004) Reconstruction of May-July precipitation in the north Helan Mountain, Inner Mongolia since AD 1726 from tree-ring late-wood widths. Chin Sci Bull 49:405-409

Liu Y, Cai QF, Shi JF, Hughes MK and others (2005) Seasonal precipitation in the south-central Helan Mountain region, China, reconstructed from tree-ring width for the past 224 years. Can J For Res 35:2403-2412

Liu Y, Sun JY, Yang YK, Cai QF and others (2007) Tree-ringderived precipitation records from inner Mongolia, China, since A.D. 1627. Tree-Ring Res 63:3-14

Liu Y, Linderholm HW, Song HM, Cai QF and others (2009) Temperature variations recorded in Pinus tabulaeformis tree rings from the southern and northern slopes of the central Qinling Mountains, central China. Boreas 38: 285-291

> Liu Y, Tian H, Song H, Liang J (2010) Tree ring precipitation reconstruction in the Chifeng-Weichang region, China, and East Asian summer monsoon variation since AD 1777. J Geophys Res 115:D06103. doi:10.1029/2009JD012330

> Liu Y, Wang C, Hao W, Song H and others (2011) Tree-ringbased annual precipitation reconstruction in Kalaqin, Inner Mongolia for the last 238 years. Chin Sci Bull 56: 2995-3002

> Ma Z, Fu C (2006) Some evidence of drying trend over northern China from 1951 to 2004. Chin Sci Bull 51:2913-2925

Pederson N, Cook ER, Jacoby G, Peteet DM, Griffin KL (2004) The influence of winter temperatures on the annual radial growth of six northern range margin tree species. Dendrochronologia 22:7-29 
Shao XM, Fan JM (1999) Past climate on West Sichuan Plateau as reconstructed from ring-widths of Dragon spruce. Quat Sci 1:81-89 (in Chinese)

Shao XM, Wu XD (1994) Tree-ring chronologies for Pinus armandi Franch. from Huashan, China. Acta Geogr Sin 49:174-181 (in Chinese)

Shi JF, Liu Y, Vaganov EA, Li JB, Cai QF (2008) Statistical and process-based modeling analyses of tree growth response to climate in semi-arid area of north central China: a case study of Pinus tabulaeformis. J Geophys Res 113:G01026. doi:10.1029/2007JG000547

Shi JF, Lu HY, Wan JD, Li SF, Nie HS (2009) Winter-half year temperature reconstruction of the last century using Pinus armandii Franch. tree-ring width chronologies in the eastern Qinling Mountains. Quat Sci 29:831-836 (in Chinese)

Shi JF, Cook ER, Lu HY, Li JB, Wright WE, Li SF (2010) Treering based winter temperature reconstruction for the lower reaches of the Yangtze River in southeast China. Clim Res 41:169-175

Song HM, Liu Y, Ni WM, Cai QF, Sun JY, Ge WB, Xiao WY (2007) Winter mean lowest temperature derived from tree-ring width in Jiuzhaihou region, China since 1750 A.D. Quat Sci 27:486-491 (in Chinese)

Stokes MA, Smiley TL (1996) An introduction to tree-ring dating. University of Arizona Press, Tucson, AZ

Editorial responsibility: Tim Sparks, Cambridge, UK
Tao F, Yokozawa M, Hayashi Y, Lin E (2003) Future climate change, the agricultural water cycle, and agricultural production in China. Agric Ecosyst Environ 95:203-215

Theurillat JP, Guisan A (2001) Potential impact of climate change on vegetation in the European Alps: a review. Clim Change 50:77-109

Tian QH, Liu Y, Cai QF, Bao G and others(2009) The maximum temperature of May-July inferred from tree-ring in Funiu Mountain since 1874 AD. Acta Geogr Sin 64: 879-887 (in Chinese)

Valentine HT (1985) Tree-growth models: derivations employing the pipe-model theory. J Theor Biol 117:579-585

> Villalba R, Veblen TT, Ogden J (1994) Climatic influences on the growth of subalpine trees in the Colorado Front Range. Ecology 75:1450-1462

Wang Y, Zhou L (2005) Observed trends in extreme precipitation events in China during 1961-2001 and the associated changes in large-scale circulation. Geophys Res Lett 32:L09707. doi:10.1029/2005GL022574

> Wigley TML, Briffa KR, Jones PD (1984) On the average value of correlated time-series, with applications in dendroclimatology and hydrometeorology. J Clim Appl Meteorol 23:201-213

Zhai P, Zhang X, Wan H, Pan X (2005) Trends in total precipitation and frequency of daily precipitation extremes over China. J Clim 18:1096-1108

Submitted: September 15, 2011; Accepted: February 29, 2012 Proofs received from author(s): June 20, 2012 